\title{
Assessment of long-lived residual radioisotopes in cement induced by neutron radiation
}

\author{
Daria Jóźwiak-Niedźwiedzka ${ }^{1, *}$, Katalin Gméling ${ }^{2}$, Ildikó Harsányi ${ }^{2}$, Kinga Dziedzic ${ }^{1}$, and \\ Michat A. Glinicki ${ }^{1}$ \\ ${ }^{1}$ Institute of Fundamental Technological Research Polish Academy of Sciences, Pawińskiego 5b, 02- \\ 106 Warsaw, Poland \\ ${ }^{2}$ Nuclear Analysis and Radiography Department, Centre for Energy Research, 29-33 Konkoly Thege \\ Miklós St. 1121, 29-33 Budapest, Hungary
}

\begin{abstract}
During the decommissioning of nuclear power plants, a significant amount of cement based composites should be disposed as radioactive waste. The use of material with low-activation constituents could effectively reduce radioactivity of concrete. The subject of the paper is the content of trace elements with large activation cross section in concrete constituents due to their ability to be activated in radiation shielding structures. Various Portland cement specimens were subjected to elemental analysis by neutron activation analysis and prompt gamma activation analysis to assess the dominant long-lived residual radioisotopes. Concentrations of the radionuclides, such as Europium-152, Cobalt-60 and Caesium-134 were assessed. Their half-life time is 13.5, 5.27, and 2.07 years, respectively. On the basis of the obtained results, recommendations for cement selection for low-activation concrete are proposed in order to economize decommissioning cost by reducing a radioactive concrete waste.
\end{abstract}

\section{Introduction}

The composition of concrete constituents significantly affects its shielding properties, so the design of special concrete to ensure safety against ionizing radiation is still the subject of many studies, [1-4]. The vast majority of published research concerned modification of the aggregate used. Main research topics range from use of aggregates characterized by high density to investigate the gamma shielding performance of concrete [1], as well as incorporating boron [2] or containing an increased amount of bound water [3] to analyze the effect of neutron flux on concrete shielding properties to the application of newly developed materials like a polyethylene- $\mathrm{B}_{4} \mathrm{C}$ based concrete for enhancing the neutron capture properties of the concrete, [4]. Definitely fewer publications concern the modification of cement and binder, $[5,6]$. Portland cement and cements containing fly ash or ground granulated blast furnace slag with specific properties i.e. low heat of hydration, resistance to alkali-silica reaction, sulphate resistance were selected to ensure the long-term performance

\footnotetext{
*Corresponding author: djozwiak@ippt.pan.pl
} 
of massive shielding concrete, [5]. Ordinary Portland cement and cement containing fly ash were analyzed by Soo and Milian, [6] to determine the influence of radiation on the mechanical integrity of cementitious materials. The differences in concrete vary by country, but all of them are influenced by radiation. Despite significant progress in the knowledge obtained in recent years about the behavior of the shielding concrete constituents as well as the concrete itself, when exposed to various types of irradiation, the process associated with the activation of concrete is not fully understood. The phenomenon of concrete activation was observed only since 1980; it is developed on the basis of creation of radioactive isotopes of certain elements that are present in concrete, [7]. The results published in 1986 by Phillips et al. [8] revealed that radiation caused by neutron flux in concrete cyclotron shields before decommissioning resulted in the formation of radioactive isotopes ${ }^{152} \mathrm{Eu}$ and ${ }^{154} \mathrm{Eu}$. At the time of decommissioning the three dominant long-lived residual radioisotopes ${ }^{60} \mathrm{Co},{ }^{152} \mathrm{Eu}$ and ${ }^{154} \mathrm{Eu}$ which are induced in concrete occupy almost $100 \%$ of the total residual radioactivity in terms of clearance levels $(C L)$ value, [12]. Their half-life is 5.275 years, 13.54 years, and 8.59 years respectively. The long-term radioactivity of special concrete with barite aggregate was analysed by Žagar et al. [9]. They found three radioisotopes ${ }^{133} \mathrm{Ba},{ }^{60} \mathrm{Co}$ and ${ }^{152} \mathrm{Eu}$ and they stated that radioactivity of analysed concrete waste will last up to 100 years. Authors indicated that the clearance levels established by International Atomic Energy Agency should be modified in order to cover correctly the radioactivity of concrete waste.

Currently, the majority of research related to the activation of shielding concrete relays on Monte Carlo simulations, [10, 11]. Park et al. [10] investigated the activation characteristics of concretes containing boron carbide and polyethylene. Their computational study revealed that the total activity levels of the concrete decreased considerably with an increase with the replacement levels of polyethylene in borated concrete. Hajdu et al. [11] simulated an irradiation scenario of concrete bunker and they have found that decay gamma dose rates of concrete activation were about $50 \%$ higher with the use of the each concrete constituent measurement-based input compared to the average overall results. They highlighted the importance of precise estimation of trace elements in materials in relation to safety planning and decommissioning of nuclear related constructions.

The subject of the paper is an assessment of long-lived residual radioisotopes induced by neutron radiation in various Portland cements intended for shielding concrete in nuclear power plants.

\section{Materials}

Four Portland cements were used in the research:

- C1 - ordinary Portland cement CEM I 42.5R with normal content of alkalis (Na2Oeq=0.56 $\%)$,

- C2 - ordinary Portland cement CEM I 52.5R with high content of alkalis $\left(\mathrm{Na}_{2} \mathrm{O}_{\mathrm{eq}}=0.88 \%\right)$,

- C3 - ordinary Portland cement CEM I 42.5R with very high content of alkalis (Na2Oeq= $1.12 \%)$, and

- C4 - Portland cement CEM I 52.5R with low content of alkalis (Na2Oeq= $0.23 \%)$ and low content of $\mathrm{Fe} 2 \mathrm{O} 3(0.3 \%)$.

Detailed chemical composition of tested cements is presented in [13].

\section{Methods}

Concentrations of major and trace elements in cements were determined by prompt gamma activation analysis (PGAA), and the assessment of the trace elements with large activation cross section was perform by neutron activation analysis (NAA), both using the $k 0$ - 
standardization method, [15]. PGAA gives precise results for major elements like $\mathrm{Si}, \mathrm{Ti}, \mathrm{Al}$, $\mathrm{Fe}, \mathrm{Mn}, \mathrm{Mg}, \mathrm{Ca}, \mathrm{Na}, \mathrm{K}$ and $\mathrm{H}$ in cement specimens. It should be emphasized that PGAA is able to measure the $\mathrm{H}$ content as well, which is not possible with most other analytical methods, [17]. PGAA is based on the detection of the prompt gamma rays (leaving the compound nuclei in $10^{-12} \div 10^{-9} \mathrm{~s}$ ) emitted by the target during neutron irradiation, while NAA utilizes the delayed gamma rays from the radioactive daughter nucleus (with short or long half-lives), measured after irradiation, [17].

All cements were oven-dried at $105^{\circ} \mathrm{C}$ for $24 \mathrm{~h}$ and they were ground into powder passing $75 \mu \mathrm{m}$ sieve.

For PGAA experiment, the specimens were sealed in teflon bags. The thickness of the packing material was $0.025 \mathrm{~mm}$. The thickness of the specimens was kept at the lowest possible value $(2-3 \mathrm{~mm})$ to minimize the effect of self-shielding and self-absorption. The irradiation and the collection of prompt-gamma spectra took place in average for one hour.

For NAA, a $150 \mathrm{mg}$ of each cement specimen was heat-sealed in high-purity quartz. The quartz ampules were wrapped in aluminum foil and encapsulated in an aluminum container. The irradiation process for NAA took 3 hours and was performed in a rotating, wellthermalized channel of the Budapest Research Reactor, [14]. Thermal neutrons is a technical term to neutrons with given energy range. Three (four) major groups are separated (cold /0$0.025 \mathrm{eV} /)$, thermal $(0.025 \mathrm{eV}-1 \mathrm{eV})$, epithermal $(1 \mathrm{eV}-1 \mathrm{keV})$ and fast $(1 \mathrm{keV}-10 \mathrm{MeV})$ neutrons.

At the same time flux-monitor foils of $\mathrm{Au}, \mathrm{Zr}$, Fe or $\mathrm{Ni}$ were co-irradiated for concentration calculations by the $k_{0}$-method, [15]. The thermal equivalent neutron flux in the rotating irradiation channel was $1.86 \times 10^{13} \mathrm{~cm}^{2} \mathrm{~s}^{-1}$. For identification of radioactive isotopes and for element concentration calculations, the KayZero for Windows 3.06 program [16] was applied.

\section{Results and discussion}

Table 1 presents the concentrations of major elements in cement obtained by PGAA method. The results of the neutron activation analysis are presented in Table 2.

Table 1. The major elemental composition of cement measured by PGAA, wt. \%.

\begin{tabular}{|c|c|c|c|c|}
\hline Element & $\mathbf{C 1}$ & $\mathbf{C 2}$ & $\mathbf{C 3}$ & $\mathbf{C 4}$ \\
\hline $\mathrm{Ca}$ & 45.00 & 45.00 & 44.00 & 47.88 \\
\hline $\mathrm{Si}$ & 9.70 & 9.40 & 9.30 & 11.99 \\
\hline $\mathrm{Al}$ & 3.00 & 2.80 & 2.60 & 1.75 \\
\hline $\mathrm{Fe}$ & 1.71 & 2.00 & 2.10 & 0.23 \\
\hline $\mathrm{S}$ & 1.21 & 1.47 & 1.72 & 0.86 \\
\hline $\mathrm{Mg}$ & 1.30 & 1.20 & 1.70 & 0.00 \\
\hline $\mathrm{K}$ & 0.83 & 0.97 & 0.99 & 0.11 \\
\hline $\mathrm{Cl}$ & 0.09 & 0.33 & 0.32 & 0.03 \\
\hline $\mathrm{Mn}$ & 0.58 & 0.27 & 0.49 & 0.01 \\
\hline $\mathrm{Na}$ & 0.17 & 0.25 & 0.38 & 0.00 \\
\hline $\mathrm{H}$ & 0.17 & 0.19 & 0.17 & 0.14 \\
\hline $\mathrm{Ti}$ & 0.17 & 0.19 & 0.17 & 0.04 \\
\hline $\mathrm{B}$ & 0.06 & 0.07 & 0.05 & 0.01 \\
\hline
\end{tabular}

The elemental composition shown in Table 1 does not show oxygen(oxygen is not measured but calculated from stoichiometry). It differs from the commonly known cement composition in which the content of individual oxides is distinguished. However, the content of individual elements and their mutual proportions are the same as in the oxide composition. The lower $\mathrm{Fe}, \mathrm{Al}$ and $\mathrm{Mg}$ content in $\mathrm{C} 4$ cement is clearly visible compared to other Portland cements, 
which corresponds to "white cement". The analyzed cements differ in their alkali content. While the content of $\mathrm{K}$ is similar for cements $\mathrm{C} 1-\mathrm{C} 3$ about $0.9 \%$, the content of $\mathrm{Na}$ varies from $0.17 \%$ for $\mathrm{C} 1,0.25 \%$ for $\mathrm{C} 2$ and $0.38 \%$ for $\mathrm{C} 3$.

Twenty three nuclides shown in Table 2 were detected with the neutron activation analysis (NAA). NAA revealed that three long-lived residual radioisotopes have been found in cements: ${ }^{152} \mathrm{Eu},{ }^{60} \mathrm{Co}$ and ${ }^{134} \mathrm{Cs}$, Table 2 . Their half-life time is $13.5,5.27$, and 2.07 years, respectively. They were subject to further analysis because these radionuclides are important in decommissioning of nuclear reactors. Very high contents of ${ }^{47} \mathrm{Ca}$ isotope as well as ${ }^{42} \mathrm{~K}$, ${ }^{59} \mathrm{Fe}$ and ${ }^{85} \mathrm{Sr}$ were found in the analyzed cement specimens. However, due to their short halflife time, they do not pose such a threat as long-lived radioactive isotopes.

Table 2. The concentrations of radionuclides in cements induced by NAA, ordered according to half-life, $\mu \mathrm{g} / \mathrm{g}$.

\begin{tabular}{|l|r|r|r|r|r|}
\hline Isotope & $\begin{array}{c}\text { Half-life, } \\
\text { days }\end{array}$ & \multicolumn{1}{c|}{ C1 } & \multicolumn{1}{c|}{ C2 } & \multicolumn{1}{c|}{ C3 } & \multicolumn{1}{c|}{ C4 } \\
\hline K-42 & 0.5 & 3787.00 & 8525.00 & 9079.00 & 891.00 \\
\hline Zn-69m & 0.6 & 558.50 & 845.30 & 401.80 & 16.56 \\
\hline As-76 & 1.1 & 5.27 & 4.45 & 12.84 & 0.80 \\
\hline Br-82 & 1.5 & 17.02 & 5.41 & 10.02 & 0.00 \\
\hline La-140 & 1.7 & 15.14 & 16.35 & 15.12 & 7.57 \\
\hline Sm-153 & 1.9 & 1.97 & 2.30 & 1.92 & 0.80 \\
\hline Yb-175 & 4.2 & 1.18 & 1.19 & 1.15 & 0.55 \\
\hline Ca-47 & 4.5 & 491900.00 & 484800.00 & 483800.00 & 465300.00 \\
\hline Nd-147 & 11.0 & 16.30 & 0.00 & 15.59 & 0.00 \\
\hline Ba-131 & 11.5 & 291.70 & 185.90 & 185.50 & 112.40 \\
\hline Rb-86 & 18.6 & 45.21 & 38.82 & 40.94 & 0.00 \\
\hline Cr-51 & 27.7 & 62.35 & 111.10 & 104.10 & 16.00 \\
\hline Ce-141 & 32.5 & 31.54 & 26.65 & 33.49 & 8.72 \\
\hline Hf-181 & 42.4 & 1.82 & 2.25 & 2.38 & 0.99 \\
\hline Fe-59 & 44.5 & 18250.00 & 21910.00 & 21000.00 & 2261.00 \\
\hline Sb-124 & 60.2 & 8.18 & 8.56 & 13.08 & 0.52 \\
\hline Sr-85 & 64.9 & 1057.00 & 827.30 & 810.10 & 1253.00 \\
\hline Tb-160 & 72.3 & 0.38 & 0.36 & 0.40 & 0.16 \\
\hline Sc-46 & 83.8 & 6.03 & 5.93 & 5.66 & 1.29 \\
\hline Ta-182 & 114.4 & 0.40 & 0.53 & 0.47 & 0.14 \\
\hline Cs-134 & 751.9 & 3.40 & 1.63 & 1.69 & 0.00 \\
\hline Co-60 & 114.4 & 7.93 & 10.44 & 11.30 & 1.79 \\
\hline Eu-152 & 4941.0 & 0.61 & 0.56 & 0.60 & 0.25 \\
\hline
\end{tabular}

The results from NAA clearly indicate the difference between ordinary Portland cements $\mathrm{C} 1$, $\mathrm{C} 2$ and $\mathrm{C} 3(\mathrm{Fe}=1.94 \pm 0.20 \%)$ and "white cement" $\mathrm{C} 4,(\mathrm{Fe}=0.23 \%)$. The content of iron was nine times higher in $\mathrm{C} 1 \div \mathrm{C} 3$ cements compared to $\mathrm{C} 4$ cement. The slight difference in the content of Potassium significantly affected the difference in the content of the isotope $\mathrm{K}$. In Cement $\mathrm{C} 1$ the content of $\mathrm{K}$ was $0.83 \%$, in $\mathrm{C} 2-0.97 \%$ and in $\mathrm{C} 3-0.99 \%$, while the content of K-42 amounted to 3700, 8500 and $9000 \mu \mathrm{g} / \mathrm{g}$, respectively. With a Potassium content of $0.11 \%$, the $\mathrm{K}$ isotope content was $900 \mu \mathrm{g} / \mathrm{g}$.

The highest content of Cs radioisotope was found in cement C1-3.4 $\mu \mathrm{g} / \mathrm{g}, \mathrm{C} 2$ and C3 cements were characterized by a similar value $1.6 \mu \mathrm{g} / \mathrm{g}$, while $\mathrm{C} 4$ cement did not contain this radioisotope. The content of Cobalt in Portland cements was between 7.93 and $11.30 \mu \mathrm{g} / \mathrm{g}$, while in cement $\mathrm{C} 4$ was only $1.79 \mu \mathrm{g} / \mathrm{g}$, almost ten times less. The content of Europium also significantly differenced, in cements $\mathrm{C} 1 \div \mathrm{C} 3$ was $0.59 \pm 0.03 \mu \mathrm{g} / \mathrm{g}$ and in cement $\mathrm{C} 4$ achieved $0.25 \mu \mathrm{g} / \mathrm{g}$. 


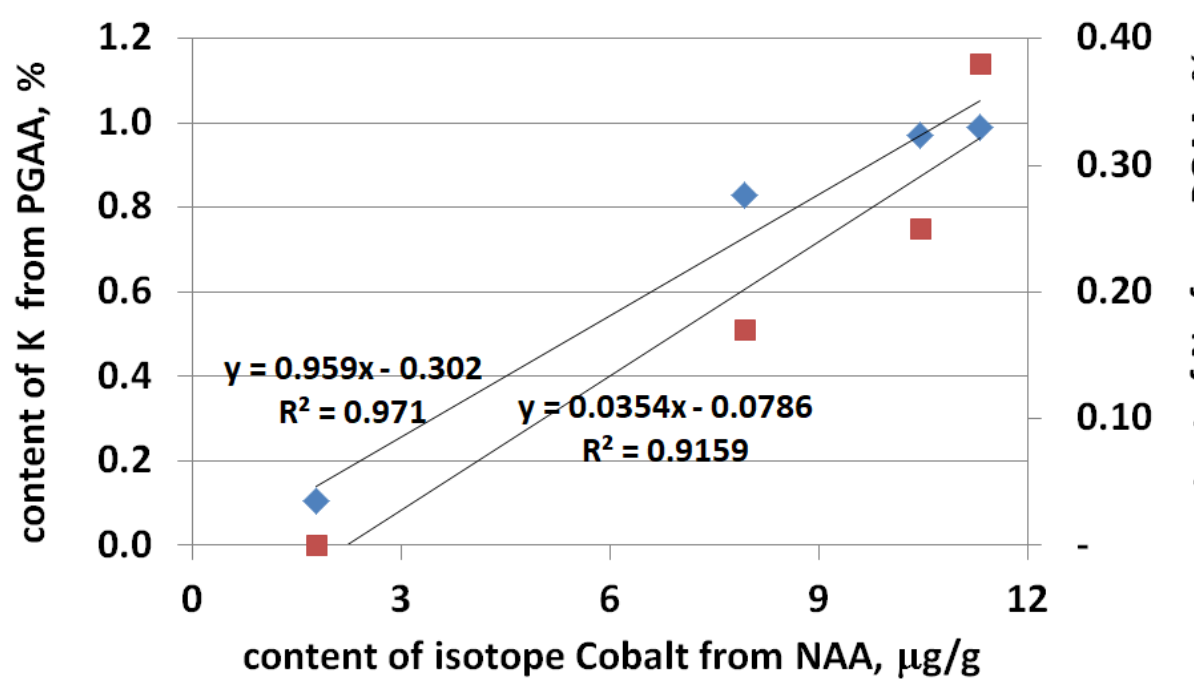

Fig. 1. Concentration of the Cobalt isotope depending on alkalis content in cement.

The conducted research has shown that the Cobalt isotope concentration in cements varied significantly depending on the alkali content, Fig. 1. The lower the alkali content in cement, the lower the Co concentration. Also, it has been noted that the content of iron in cement clearly influenced the concentration of Europium isotope, Fig. 2. The concentration of Eu increased with increasing Fe content in cement. Almost ideal linear dependence $\left(\mathrm{R}^{2}=0.992\right)$ of Fe content in cement of the amount of Fe radioisotope formed was found, Fig. 2 .



Fig. 2. Concentration of the isotopes Europium and iron depending on Fe content in cement.

Similar results were obtained by Kimura et al. [18]. Their radioactive analysis showed that $\mathrm{Co}$ and $\mathrm{Eu}$ were the major target elements which decided the radioactivity level of reinforced concrete made from typically aggregates and cements. Suzuki et al. [12] analyzed the activated radioactivities of ${ }^{60} \mathrm{Co},{ }^{152} \mathrm{Eu}$ and ${ }^{134} \mathrm{Cs}$ in biological shielding concrete and evaluated them for the clearance level. The average concentrations of ${ }^{60} \mathrm{Co},{ }^{134} \mathrm{Cs}$ and ${ }^{152} \mathrm{Eu}$ 
formed in their concrete were 21.9, 3.21 and $1.08 \mathrm{ppm}$, respectively. The same relationship was obtained in the conducted tests. The highest concentration of long-lived isotopes was found for ${ }^{60} \mathrm{Co}$, then ${ }^{134} \mathrm{Cs}$ and the smallest for ${ }^{152} \mathrm{Eu}$.

The research performed by Suzuki et al. [12] has shown that the average concentration of ${ }^{60} \mathrm{Co},{ }^{152} \mathrm{Eu}$ and ${ }^{134} \mathrm{Cs}$ in cements was 11.9 (S.D. 8.6), 1.15 (S.D. 0.85) and 5.86 (S.D. 4.39) $\mathrm{ppm}$. The mean concentration of ${ }^{60} \mathrm{Co}$ formed in cement decreased in following order: moderate heat cement, fly ash cement (CEM II, without distinction between A and B), Portland cement, Portland blast-furnace slag cement (CEM III), and high alumina cement. The mean concentrations of ${ }^{152} \mathrm{Eu}$ formed in all kinds of cement decreased in following order: fly ash cement, Portland blast-furnace slag cement, high alumina cement, Portland cement, and moderate heat cement. The reasons of high concentrations of ${ }^{152} \mathrm{Eu}$ formed in fly ash cement and blast-furnace slag cement was due to the presence of high concentrations of ${ }^{152} \mathrm{Eu}$ in coal ash and coal slag. Some normal and white Portland cements were characterized by very low concentration of ${ }^{60} \mathrm{Co}$ (less than $1 \mathrm{ppm}$ ) and ${ }^{152} \mathrm{Eu}$ (lower than $0.3 \mathrm{ppm}$ ). The conducted research also shows that "white cement" C4 among the Portland cements tested had the lowest concentration of long-lived isotopes. The concentration of ${ }^{60} \mathrm{Co}$ was equal 1.79 $\mu \mathrm{g} / \mathrm{g}$ and ${ }^{152} \mathrm{Eu}$ equal $0.25 \mu \mathrm{g} / \mathrm{g}$ and no ${ }^{134} \mathrm{Cs}$ was found.

The phenomenon of concrete activation may expose personnel to hazardous radiation during fuel transport and as well as during routine maintenance or NPP inspections. Such a threat may also appear after decommissioning of nuclear power plant. The potential activation of elements in concrete should be minimalized. The cement should be carefully selected to contain as low as possible concentration of dominant long-lived residual radioisotopes, while maintaining all the required parameters related to strength and durability. The relationships between the elemental composition of cement and estimation of trace elements with large activation cross section will complement the knowledge on the design of low-activation concrete. Research on special aggregate and concrete activation is currently ongoing.

\section{Conclusions}

The following conclusions can be drawn:

- Application of neutron activation analysis and prompt gamma activation analysis allows for a preselection of low-activation cement based on its elemental composition.

- Three major long-lived residual radioisotopes were found in cements: ${ }^{152} \mathrm{Eu},{ }^{60} \mathrm{Co}$ and ${ }^{134} \mathrm{Cs}$.

- For the considered range of Portland cements CEM I 42.5R and 52.5 R the content of Co was proportional to the content of alkalis and the content of Eu was proportional to the total content of $\mathrm{Fe},(\mathrm{Fe} 2+$ and $\mathrm{Fe} 3+, \mathrm{Fe} 2 \mathrm{O} 3(\mathrm{~T})$; $\mathrm{T}=\mathrm{Total}$, all $\mathrm{Fe} 2+$ and $\mathrm{Fe} 3+$ ions $)$.

- The cement with the low content of $\mathrm{Fe}$ and $\mathrm{Al}$ (white cement) was characterized by the lowest content of long-lived residual radioisotopes, making it suitable for low-activation concrete.

\section{Acknowledgements}

The research was supported by Polish National Centre for Research and Development (Project V4-Korea/2/2018) and project No. 127102 that has been implemented with the support from the National Research, Development and Innovation Fund of Hungary, financed under the NN_17 V4-Korea funding scheme. 


\section{References}

1. I. Akkurt, C. Basyigit, S. Kilincarslan, B. Mavi, A. Akkurt, Cem. Concr. Compos. 28 (2) 153-157 (2006)

2. O. Gencel, Gamma and neutron shielding characteristics of concretes containing different colemanite proportions (Nuclear Science and Technology, 41-49, 2012)

3. W. A. Kansouh, Ann. Nucl. Energy 47, 258-263(2012)

4. D. D. Di Julio, C. P. Cooper-Jensen, H. Perrey, K. Fissum, E. Rofors, J. Scherzinger, P. M. Bentley, Nucl. Instruments Methods Phys. Res. Sect. A Accel. Spectrometers, Detect. Assoc. Equip. 859, 41-46 (2017)

5. T. Baran, M. A. Glinicki, D. Jóźwiak-Niedźwiedzka, Cement Lime Concrete 21, 4, 207 216 (2016)

6. P. Soo, L. M. Milian, J. Mater. Sci. 20, 14, 1345-1348 (2001)

7. A. M. Brandt, D. Jóźwiak-Niedźwiedzka, Cement Lime Concrete 18 (4),1-22 (2013)

8. A. B. Phillips, D. E., Prull, R. A. Ristinen, J. J Kraushaar, Health Phys. 51, 337-342 (1986)

9. T. Žagar, M. Božič, M. Ravnik, J. Nucl. Mater. 335, 379-386 (2004)

10. S. J. Park, J. G. Jang, H. K. Lee, J. Nucl. Mater. 452 (1-3), 205-211 (2014)

11. D. Hajdu, E. Dian, K. Gmeling, E. Klinkby, C. P. Cooper-Jensen, J. Osan, P. Zagyvai, Sep. 27, 29 (2019)

12. A. Suzuki, T. Iida, J. Moriizumi, Y. Sakuma, J. Takada, K. Yamasaki, T. Yoshimoto, J. Nucl. Sci. Technol. 38, 7, 542-550 (2001)

13. D. Jóźwiak-Niedźwiedzka, K. Gméling, A. Antolik, K. Dziedzic, M. A. Glinicki, Constr. Build. Mater. (in review) (2020)

14. L. Szentmiklósi, D: Párkányi, I. Sziklai-László, J. Radioanal. Nucl. Chem. 309, 91-99 (2016)

15. L. Szentmiklósi, B. Maróti, D. Párkányi, I.Harsányi, Z. Révay, J. Radioanal. Nucl. Chem. 315, 743-750 (2018)

16. F. De Corte, R. Van Sluijs, A. Simonits, J. Kučera, B. Smodiš, A.R. Byrne, A. De Wispelaere, D. Bossus, J. Frána, Z. Horák, R. Jaimovi, Appl. Radiat. Isot. 55(3), 347354 (2001)

17. K. Gméling, A. Simonits, I. Sziklai László, D. Párkányi, J. Radioanal. Nucl. Chem. 300, 507-516 (2014)

18. K. I. Kimura, A. Hasegawa, K. Hayashi, M. Uematsu, T. Ogata, T. Tanosaki, R. Yoshino, M. Sato, M. Saito, M. Kinno, Proc. $16^{\text {th }}$ International Conference on Nuclear Engineering (ICONE16, Orlando, USA, ICONE16-48484, 1-10, 2008) 